\title{
Constraining the roughness degree of slip heterogeneity
}

\author{
Mathieu Causse, ${ }^{1}$ Fabrice Cotton, ${ }^{1}$ and P. M. Mai ${ }^{2}$ \\ Received 2 July 2009; revised 17 November 2009; accepted 1 December 2009; published 7 May 2010.
}

[1] This article investigates different approaches for assessing the degree of roughness of the slip distribution of future earthquakes. First, we analyze a database of slip images extracted from a suite of 152 finite-source rupture models from 80 events $\left(M_{w}=4.1-8.9\right)$. This results in an empirical model defining the distribution of the slip spectrum corner wave numbers $\left(k_{c}\right)$ as a function of moment magnitude. To reduce the "epistemic" uncertainty, we select a single slip model per event and screen out poorly resolved models. The number of remaining models (30) is thus rather small. In addition, the robustness of the empirical model rests on a reliable estimation of $k_{c}$ by kinematic inversion methods. We address this issue by performing tests on synthetic data with a frequency domain inversion method. These tests reveal that due to smoothing constraints used to stabilize the inversion process, $k_{c}$ tends to be underestimated. We then develop an alternative approach: (1) we establish a proportionality relationship between $k_{c}$ and the peak ground acceleration (PGA), using a $k^{-2}$ kinematic source model, and (2) we analyze the PGA distribution, which is believed to be better constrained than slip images. These two methods reveal that $k_{c}$ follows a lognormal distribution, with similar standard deviations for both methods.

Citation: Causse, M., F. Cotton, and P. M. Mai (2010), Constraining the roughness degree of slip heterogeneity, J. Geophys. Res., 115, B05304, doi:10.1029/2009JB006747.

\section{Introduction}

[2] Kinematic inversion methods are routinely used to estimate the slip distribution on the fault surface during earthquake rupture. Thus, a significant number of earthquake slip models for past earthquakes is now available. A current topic of engineering seismology is to analyze these inverted slip images for characterizing the slip distribution of hypothetical future earthquakes [Somerville et al., 1999; Mai and Beroza, 2002; Mai et al., 2005; Manighetti et al., 2005; Lavallée et al., 2006]. For the prediction of strong ground motion, a crucial feature of the slip distribution is its degree of heterogeneity, which strongly affects the highfrequency seismic radiation. The goal of this paper is to gain some insights so as to better constrain this degree of slip heterogeneity for future events.

[3] In many theoretical studies, the slip distribution complexity is described by the amplitude Fourier spectrum. Hanks [1979] assumed that the slip on the fault plane depends on the radial wave number $k$ as $k^{-n}$. On the basis of the hypothesis of self-similarity, he found $n=2$. Frankel [1991] proposed a composite source model in which an earthquake is composed of a fractal distribution of small events. He demonstrated that a fractal dimension of 2 leads

\footnotetext{
${ }^{1}$ Laboratoire de Géophysique Interne et Tectonophysique, CNRS, Institut de Recherche pour le Développement, Université Joseph Fourier, Grenoble, France.

${ }^{2}$ Division of Physical Sciences and Engineering, King Abdullah University of Science and Technology, Thuwal, Saudi Arabia.

Copyright 2010 by the American Geophysical Union. 0148-0227/10/2009JB006747
}

to the commonly observed $\omega^{-2}$ spectral decay of the displacement amplitude spectrum under the assumption of selfsimilarity. This also corresponds to a wave number spectrum of slip decaying as $k^{-n}$. On the basis of that concept, Herrero and Bernard [1994] developed a kinematic source model in which the static slip is defined in the spectral domain by a $k^{-2}$ falloff beyond the inverse of a characteristic rupture length $L_{c}$, which thus constrains a corner wave number, $k_{c} \propto$ $1 / L_{c}$. They showed that such slip distributions, together with a constant rupture velocity and a specific $k$-dependent risetime, lead to the $\omega^{-2}$ spectral falloff. In this model, the highfrequency seismic radiation is thus fully explained by slip heterogeneities.

[4] Somerville et al. [1999] studied a set of 15 slip models obtained from the inversion of low-pass-filtered, nearsource ground-motion recordings and teleseismic data. They showed that the static slip wave number spectra are well fitted by a $k^{-2}$ model. Assuming self-similarity, they proposed an empirical model to assess the distribution of the corner wave number $k_{c}$ (beyond which the spectra have power-law decay) as a function of moment magnitude for representing future earthquakes. The corner wave number can then be defined as $k_{c}=K / L_{c}$, where $K$ is a dimensionless constant. Since $k_{c}$ controls the amplitude of slip heterogeneities at different scale lengths, $k_{c}$ can be seen as a measure for the roughness degree of the slip distribution. For a given characteristic fault length $L_{c}$, small values of $K$ result in one large, smooth asperity. For larger values of $K$, the gradient of the slip distribution increases and the slip models become rougher and contain more small-scale slip heterogeneities (Figure 1). Gallovic and Brokesova [2004] 


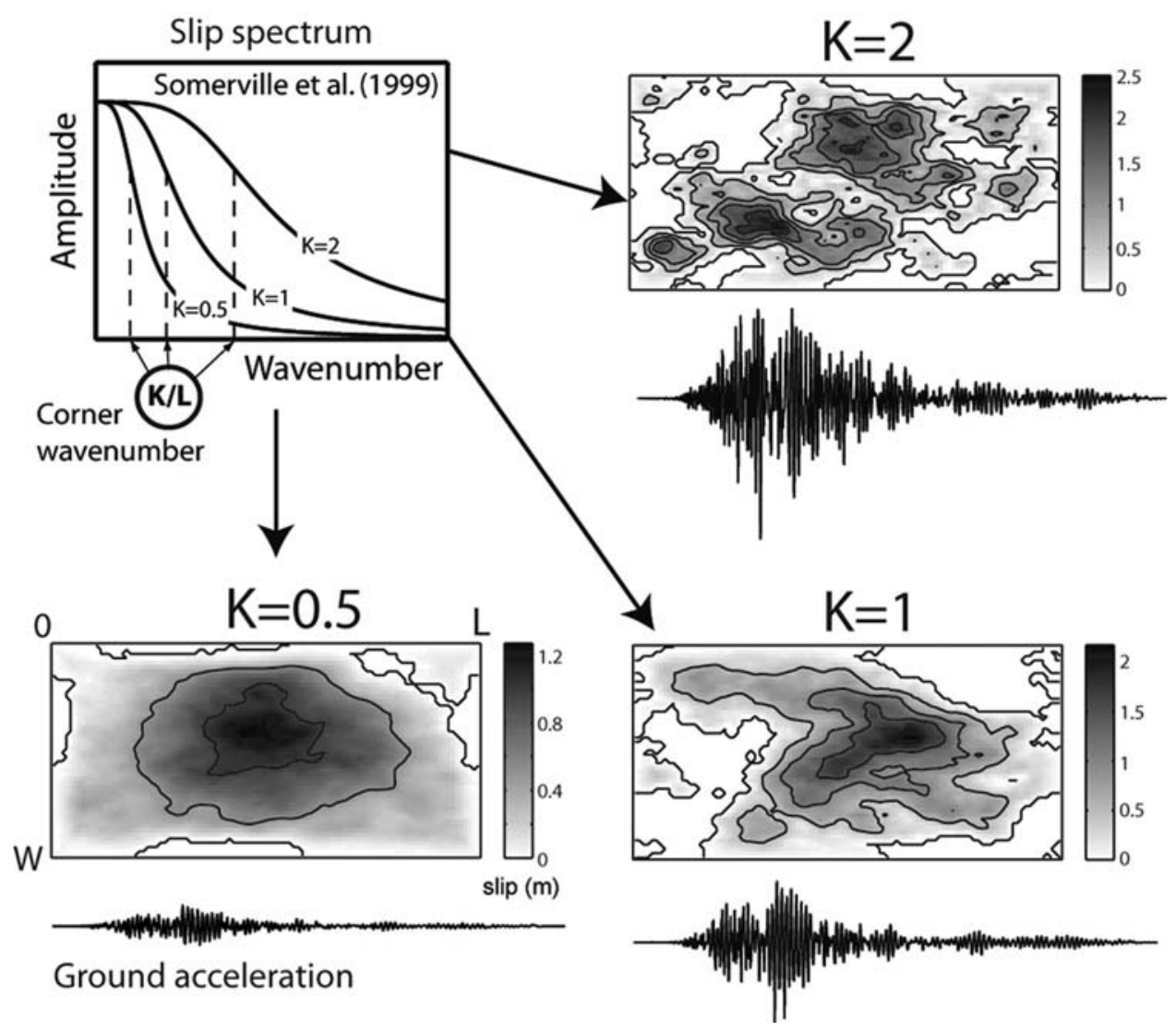

Figure 1. Example of static slip distributions following a $k^{-2}$ spectral decay for different corner wave number values (the mean slip equals $0.4 \mathrm{~m}$ ). Also shown are examples of simulated accelerograms, assuming a constant rupture velocity [Causse et al., 2009]. The case $K=0.5$ results in smooth slip distributions and low-amplitude ground motions. On the contrary, the case $K=2$ leads to highly heterogeneous static slip and to large, high-frequency ground-motion amplitude.

established that in the case of a unilateral rupture, the spectral amplitude level of the far-field ground acceleration is proportional to $K^{2}$. Consequently, the high-frequency ground motion is strongly sensitive to the slip roughness parameter $K$ (Figure 1). For realistic ground-motion simulations due to future earthquakes, it is thus imperative to properly a priori estimate this slip roughness distribution.

[5] Studying the slip roughness through an empirical approach as proposed by Somerville et al. [1999] offers the advantage of assessing the roughness variability due to the natural variability of the source process for a given magnitude. However, the results of Somerville et al. [1999] are based on a rather small number of earthquake models, which restricts the reliability of the derived empirical model. The objective of our study is thus to investigate different approaches for improving the assessment of the slip roughness. We first update the model of Somerville et al. [1999] by analyzing a larger database of finite-source rupture models (http://www.seismo.ethz.ch/srcmod), composed of 152 rupture models from earthquakes of magnitude 4.1-8.9. In order to reduce the "epistemic" uncertainty in earthquake source models (due to a variety of inversion techniques and corresponding parameterizations, as well as data selection and data processing issues), we first examine the database to extract the particularly well resolved and reliable models.
The number of remaining slip distributions $(\sim 30)$ is thus still rather small.

[6] Furthermore, the robustness of the proposed $k_{c}$ distribution rests on a reliable estimation of the $k_{c}$ values in the database. Should we consider kinematic inversion methods as a relevant tool to retrieve the slip roughness? This issue is addressed by performing a set of tests on synthetic data with a frequency domain inversion method. These tests reveal that the smoothing constraints used to stabilize the inversion process tend to underestimate the slip roughness.

[7] We then develop an alternative method to better constrain the roughness variability by establishing a relationship between $k_{c}$ and peak ground acceleration (PGA), which is usually better constrained than slip images.

\section{Analysis of Inverted Slip Images}

[8] Following the approach of Somerville et al. [1999], we study the static slip roughness by analyzing the distribution of $k_{c x}$ and $k_{c y}$, the corner wave numbers along strike and along dip, respectively. Our initial database is composed of 152 slip images from 80 events with moment magnitudes ranging from 4.1 to 8.9 . These slip distributions are then carefully examined to extract only those that are useful for a reliable estimation of $k_{c x}$ and $k_{c y}$. 


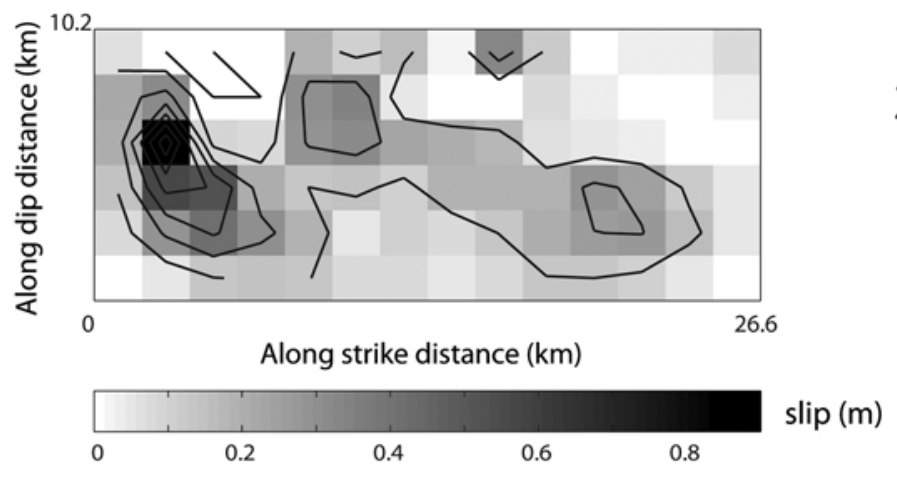

\section{Parkfield earthquake $\left(M_{\mathrm{w}}=6\right)$}

Dreger et al. (2005)
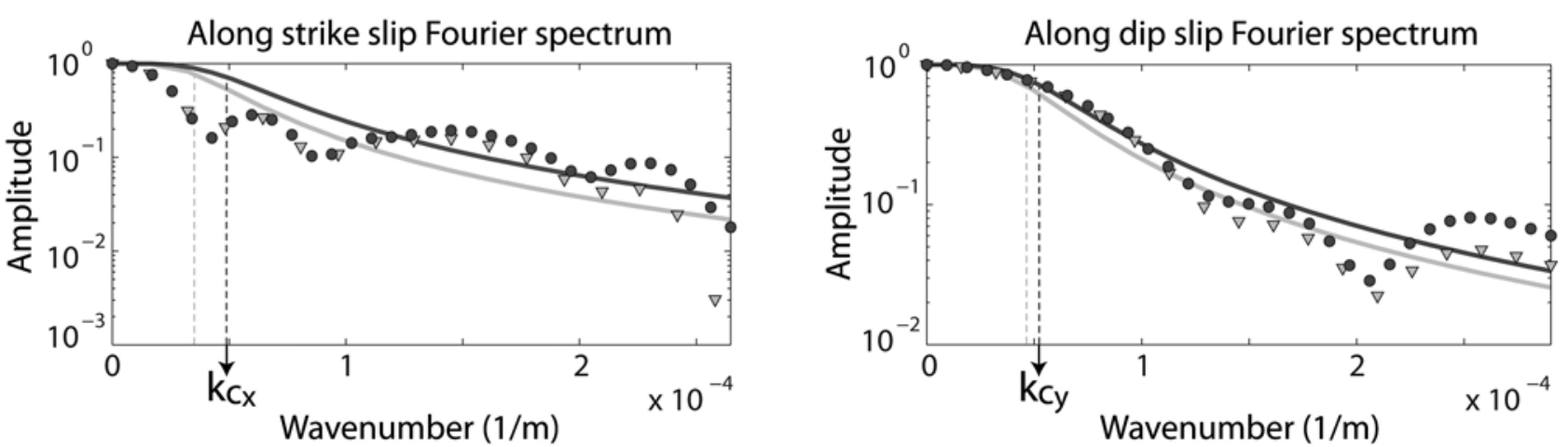

Figure 2. Example of a corner wave number calculation for the slip image derived by Dreger et al. [2005] for the 2004 Parkfield earthquake. The corner wave number values are derived from the raw slip distributions. The effect of resampling the slip image at $1 \mathrm{~km}$ spacing by bilinear interpolation [Somerville et al., 1999] is also shown. The dashed light-gray lines indicate lower values of $k_{c x}$ and $k_{c y}$ obtained for the interpolated slip maps, implying a smoother slip distribution than given by the original one.

\subsection{Method}

\subsubsection{Slip Image Processing and Corner Wave Number Calculation}

[9] Slip distributions obtained with multisegment discontinuous fault models are first eliminated, as well as the 1987 Superstition Hills case, for which the slip occurred in three subevents on the same fault but at delayed times. In contrast to Somerville et al. [1999] and Mai and Beroza [2002], we do not interpolate the slip images to increase and equalize the spatial sampling. Indeed, Lavallée et al. [2006] showed that the interpolation can result in a spurious estimation of the corner wave number (see also Figure 2). Next, following Somerville et al. [1999], we redefine the dimensions of the rectangular fault planes by removing the edge subfault rows or columns with slip less than $30 \%$ of the mean slip. This process ensures a uniform definition of effective rupture area. Slip models with fewer than five subfaults along strike or dip are then removed to keep at least three points in the Fourier domain. This reduces the number of models to 108 and 96 for the along-strike and along-dip analyses, respectively. The trimmed slip models are padded with zero-slip subfaults to achieve 256 subfaults along each direction for wave number-spectra calculation

[10] The along-strike and along-dip corner wave numbers are defined as $k_{c x}=K_{x} / L$ and $k_{c y}=K_{y} / W$, respectively. The along-strike and along-dip amplitude spectra of each slip image are calculated by 2-D Fourier analysis. The spectra are normalized and compared to a theoretical 1-D $k^{-2}$ model defined according to (Figure 2)

$$
D_{\bmod }(k)=\frac{1}{\sqrt{1+\left(k / k_{c}\right)^{4}}} .
$$

The parameters $k_{c x}$ and $k_{c y}$ are assessed by minimizing the misfit $E$ expressed as

$$
E=\sum_{k \in\left[0, k_{N}\right]}\left[\log \left(D_{\mathrm{obs}}(k)\right)-\log \left(D_{\bmod }(k)\right)\right]^{2},
$$

where $k_{N}$ is the Nyquist wave number. Since fault planes are commonly assumed to be rectangular and split into square subfaults, the number of along-dip subfaults is generally lower. We then expect the resolution of the along-dip corner wave number $k_{c x}$ to be lower.

\subsubsection{Empirical Model}

[11] According to classical source-scaling theory [e.g., Brune, 1970], the seismic moment $M_{0}$ scales with the cube of a characteristic fault dimension, $L_{c}: M_{0} \propto\left(L_{c} / K\right)^{3}$. The definition of magnitude moment $\left(M_{w}=\frac{2}{3} \log M_{0}+\right.$ cst $)$ gives $M_{w} \propto 2 \log \left(L_{c} / K\right)+$ cst. This results in the following model: $\log \left(k_{c}\right)=a-0.5 M_{w}$. In our 2-D analysis, it leads to

$$
\begin{aligned}
& \log \left(k_{c x}\right)=a_{x}-0.5 M_{w} \\
& \log \left(k_{c y}\right)=a_{y}-0.5 M_{w} .
\end{aligned}
$$


a) "Raw" results

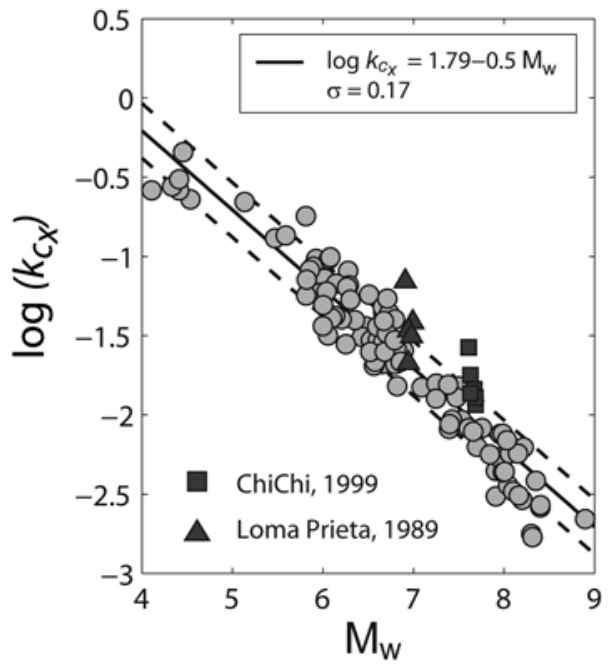

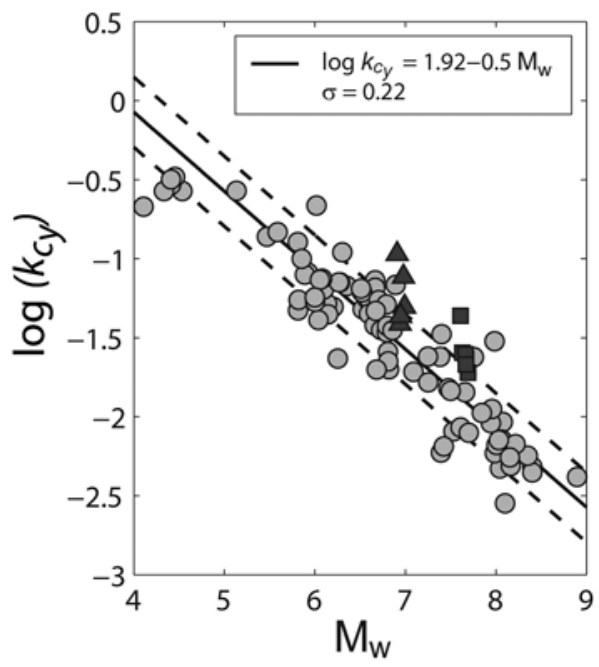

\section{b) Results after the model selection}

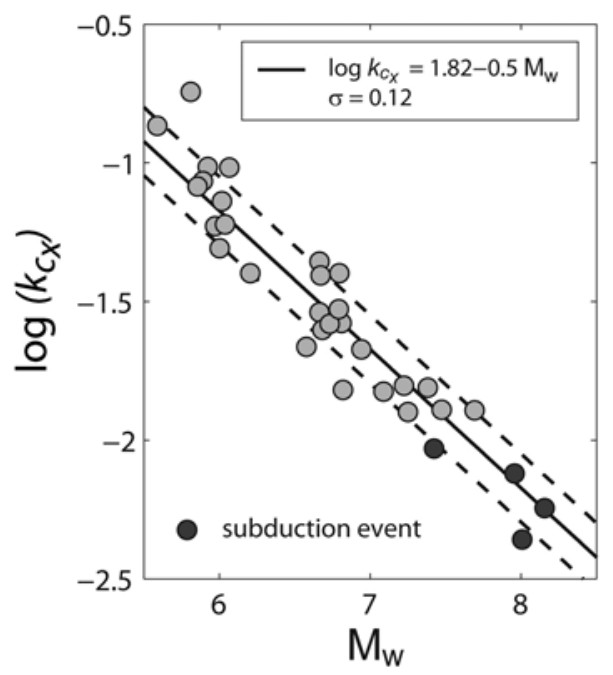

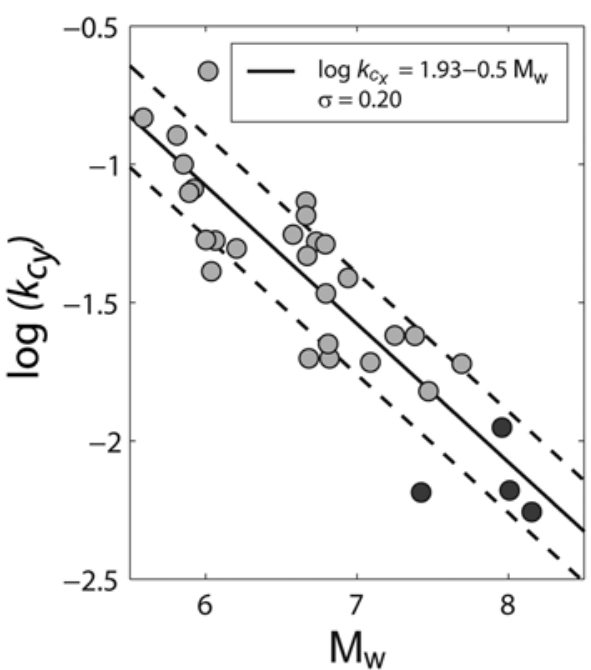

Figure 3. (a) Corner wave number values (along-strike results on the left and along-dip results on the right) derived from the spectral analysis of the slip image database (http://www.seismo.ethz.ch/srcmod). For illustrating the "epistemic" uncertainty, the particular cases of the Chi Chi and the Loma Prieta earthquakes are represented by triangles and squares, respectively. The black lines stand for the resulting empirical model (median \pm sigma) based on self-similarity. (b) The same as Figure 3a, but after selecting one model per event and screening out poorly resolved models (Table 1). Subduction events are indicated in dark gray.

According to Somerville et al. [1999], the corner wave number values are approximately lognormally distributed. We therefore test the hypothesis that the residuals of $\log _{10}\left(k_{c x}\right)$ (respectively, $\left.\log _{10}\left(k_{c y}\right)\right)$ are drawn from a centered normal distribution with standard deviation $\sigma\left[\log _{10}\left(k_{c x}\right)\right]$ (respectively, $\sigma\left[\log _{10}\left(k_{c y}\right)\right]$ ) using the Kolmogorov-Smirnov (KS) test. The constant $a_{x}$ and $a_{y}$ and the standard deviation values are computed by means of Monte Carlo simulations, so that the largest $p$ value of the KS test is obtained.

\subsection{Slip Model Selection}

[12] The standard deviation terms are composed of two types of uncertainties. First, the "aleatory variability" is inherent to the unpredictable nature of future events [Toro et al., 1997]. In the context of this study, it can be defined as the natural dispersion of the corner wave number values around the theoretical model. On the other hand, the "epistemic uncertainty" comes from incorrect estimates of the $k_{c}$ value. Indeed, there is a large variability in the inverted slip distributions obtained by different authors, which results in significantly different $k_{c}$ values (e.g., the 1999 Chi Chi earthquake; see Figure 3a). The epistemic uncertainty also arises from incomplete knowledge about the physics of the rupture process. For instance, the empirical model (equation (3)) is based on the principle of self-similarity, which is a controversial topic in the context of earthquake 
Table 1. Selected Slip Models ${ }^{\mathrm{a}}$

\begin{tabular}{|c|c|c|c|c|}
\hline No. & Location & Date & $M_{w}$ & Reference \\
\hline 1 & Fukuoka & 20 Mar 2005 & 6.7 & Asano et al. [2005] \\
\hline 2 & Parkfield & 28 Sep 2004 & 6.0 & Dreger et al. [2005] \\
\hline 3 & Tokachi-oki & 25 Sep 2003 & 8.2 & Yagi [2004] \\
\hline 4 & Boumerdes & 21 May 2003 & 7.2 & Semmane et al. [2005a] \\
\hline 5 & Geiyo & 24 Mar 2001 & 6.8 & Sekiguchi and Iwata [2002] \\
\hline 6 & Bhuj & 23 Jan 2001 & 7.6 & Antolik and Dreger [2003] \\
\hline 7 & Tottori & 6 Oct 2000 & 6.7 & Semmane et al. [2005b] \\
\hline 8 & Oaxaca & 30 Sep 1999 & 7.5 & Hernandez et al. [2001] \\
\hline 9 & Chi Chi & 20 Sep 1999 & 7.6 & Ma et al. [2001] \\
\hline 10 & Kogashima & 26 Mar 1997 & 6.0 & Miyakoshi et al. [2000] \\
\hline 11 & Colfiorito & 14 Oct 1997 & 5.8 & Hernandez et al. [2004] \\
\hline 12 & Hyuga-nada & 2 Dec1996 & 6.7 & Yagi et al. [1999] \\
\hline 13 & Hyuga-nada & 19 Oct 1996 & 6.8 & Yagi et al. [1999] \\
\hline 14 & Colima & 9 Oct 1995 & 8.0 & Mendoza and Hartzell [1999] \\
\hline 15 & Northridge & 17 Jan 1994 & 6.7 & Wald et al. [1996] \\
\hline 16 & Sierra Madre & 28 Jun 1991 & 5.6 & Wald [1992] \\
\hline 17 & Ungava & 25 Dec 1989 & 6.0 & Hartzell et al. [1994] \\
\hline 18 & Loma Prieta & 18 Oct 1989 & 6.9 & Wald et al. [1991] \\
\hline 19 & Saguenay & 25 Nov 1988 & 5.8 & Hartzell et al. [1994] \\
\hline 20 & Whittier Narrows & 1 Oct 1987 & 5.9 & Hartzell and Iida [1990] \\
\hline 21 & North Palm Springs & 8 Jul 1986 & 6.2 & Hartzell [1989] \\
\hline 22 & Nahanni & 23 Dec 1985 & 6.6 & Hartzell et al. [1994] \\
\hline 23 & Nahanni & 5 Oct 1985 & 6.6 & Hartzell et al. [1994] \\
\hline 24 & Zihuatanejo & 21 Sep 1985 & 7.4 & Mendoza [1993] \\
\hline 25 & Michoacan & 19 Sep 1985 & 8.0 & Mendoza and Hartzell [1989] \\
\hline 26 & Morgan Hill & 24 Apr 1984 & 6.0 & Hartzell and Heaton [1986] \\
\hline 27 & Borah Peak & 28 Oct 1983 & 6.8 & Mendoza and Hartzell [1988] \\
\hline 28 & Imperial Valley & 15 Oct 1979 & 6.6 & Hartzell and Heaton [1983] \\
\hline 29 & Coyote Lake & 6 Aug 1979 & 5.9 & Liu and Helmberger [1983] \\
\hline 30 & Tabas & 16 Sep 1978 & 7.1 & Hartzell and Mendoza [1991] \\
\hline
\end{tabular}

${ }^{\mathrm{a} E v e n t s}$ and inversion models were selected in the database of finitesource rupture models (http://www.seismo.ethz.ch/srcmod).

source physics [e.g., Kanamori and Rivera, 2004; Beeler et al., 2003; Ide and Beroza, 2001; Mai and Beroza, 2000]. The simplicity of the model necessarily requires combining both aleatory and epistemic uncertainties. Rather than defining a more complicated model, we propose to reduce the epistemic uncertainty by selecting slip images from the entire database according to several criteria. First, we keep only one slip image per earthquake, giving priority to those models derived by combining data of different types (strong motion, teleseismic, GPS, interferometric synthetic aperture radar). The joint inversion of multiple data sets is expected to increase the resolution power [Delouis et al., 2002]. Second, we remove the images derived from GPS data only or which use data from only a small number of strong motion stations $(<10)$. The selected models are shown in Table 1.

\subsection{Results}

[13] Figures 3a and 3b display the empirical models established from the overall database and from the selected slip images of Table 1, respectively. The $p$ values of the
KS test equal 0.99 in both cases. This indicates that $k_{c x}$ and $k_{c y}$ are well described with a lognormal distribution. Note that $\sigma\left[\log _{10}\left(k_{c y}\right)\right]$ is larger than $\sigma\left[\log _{10}\left(k_{c x}\right)\right]$, which reflects the lower resolution of $k_{c y}$. The model selection leads to a significant decrease of the epistemic uncertainty, and $\sigma\left[\log _{10}\left(k_{c x}\right)\right]$ decreases from 0.17 to 0.12 . Nevertheless, this selection process implies a strong reduction of the number of usable slip models, which drops from 108 (respectively, 96) to 32 (respectively, 30).

[14] Table 2 shows the comparison between the derived empirical model with slip image selection and the one of Somerville et al. [1999]. The obtained median model is similar for $k_{c x}$ but slightly exceeds the one of Somerville et al. [1999] for $k_{c y}$ (about $+25 \%$ ). This is partly due to their slip data interpolation process, which significantly reduces the $k_{c y}$ values (Figure 2). Finally, our study results in a significant reduction of the corner wave number variability.

[15] For fixed rupture dimensions $(L, W)$ our empirical model provide the distribution of the dimensionless roughness parameters $K_{x}$ and $K_{y}$. These distributions can be used to generate populations of scenario source models for groundmotion simulation due to a future earthquake, following the $k^{-2}$ source model.

\section{Can We Trust Inversion Methods to Retrieve the Slip Roughness?}

[16] Characteristics of the static slip distribution can be analyzed in detail to constrain the rupture process of future earthquakes. This is the principle followed in section 1 , in which a database of slip models of past events is used to define the slip roughness for potential future events. However, many studies point out the large degree of uncertainties in inverted rupture models [Beresnev, 2003; Hartzell et al., 2007; Mai et al., 2007], and hence we have to first examine the accuracy of measuring slip roughness depending on the slip model variability.

[17] Since it is not possible to compare inverted static slip to the real slip that occurred during earthquakes, a possible way to test the reliability of inversion procedures is to work on synthetic data created from hypothesized kinematic ruptures and investigate to what extent the input slip can be recovered [Olson and Anderson, 1988; Graves and Wald, 2001; Delouis et al., 2002]. Following this idea, we carry out a suite of synthetic tests to investigate the ability of a particular inversion method to retrieve the slip roughness.

\subsection{Inversion Method}

[18] The inversion technique we deploy has been applied to study many major earthquakes: the 1992 Landers earthquake [Cotton and Campillo, 1995; Hernandez et al., 1999], the 1999 Oaxaca event [Hernandez et al., 2001], the 1997

Table 2. Distribution of the Corner Wave Numbers of Slip Distributions ${ }^{\mathrm{a}}$

\begin{tabular}{|c|c|c|c|}
\hline Method & Median Empirical Model & Distribution Type & Standard Deviation \\
\hline \multirow[t]{2}{*}{ Somerville et al. [1999] } & $\log \left(k_{c x}\right)=1.72-0.5 M_{w}$ & lognormal & 0.26 \\
\hline & $\log \left(k_{c y}\right)=1.93-0.5 M_{w}$ & lognormal & 0.26 \\
\hline \multirow[t]{2}{*}{ Slip inversion analysis (Table 1 ) } & $\log \left(k_{c x}\right)=1.82-0.5 M_{w}$ & lognormal & 0.13 \\
\hline & $\log \left(k_{c y}\right)=1.93-0.5 M_{w}$ & lognormal & 0.20 \\
\hline Ground-motion-based approach & - & lognormal & 0.12 \\
\hline
\end{tabular}

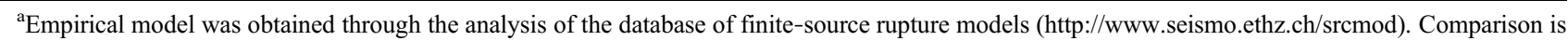
made with the study of Somerville et al. [1999] and the alternative ground-motion based approach developed in this paper. 


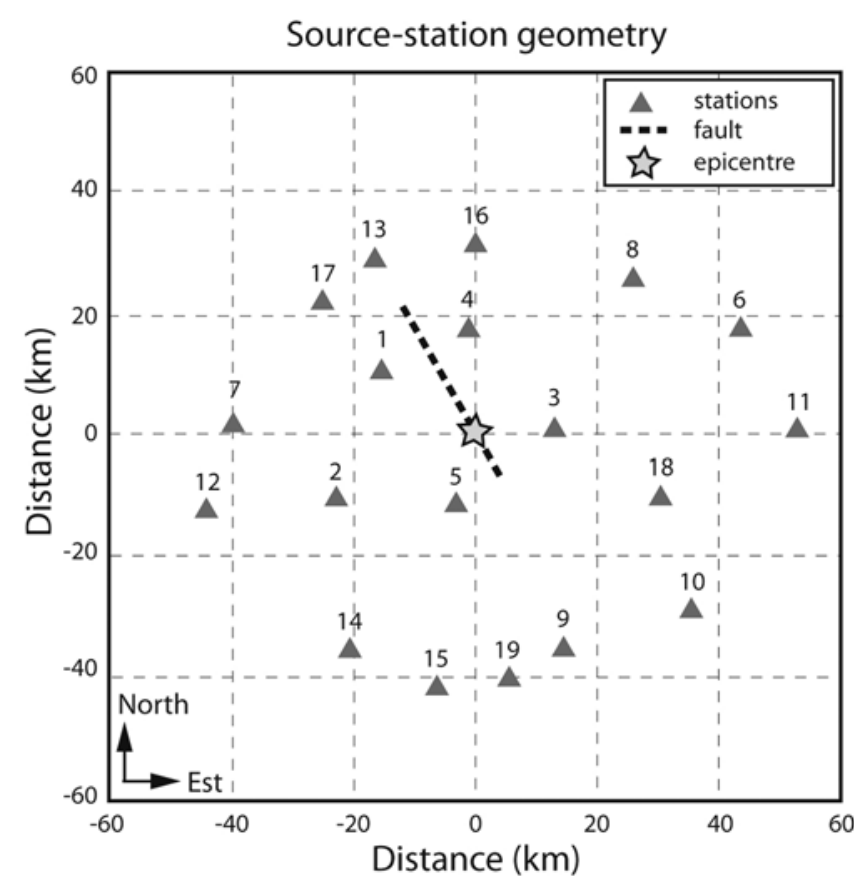

Figure 4. Fault plane geometry and network of stations used in the synthetic tests; the dashed line marks the surface trace of the vertical fault. The layout of the stations around the fault and the velocity-density structure are the ones adopted for the Blindtest on Earthquake Source Inversion [Mai et al., 2007].

Colfiorito earthquake sequence [Hernandez et al., 2004], the 2000 Tottori earthquake [Semmane et al., 2005a], and the 2003 Boumerdes event [Semmane et al., 2005b]. The procedure enables us to retrieve the rupture history by inverting strong ground-motion data in the frequency domain.

\subsubsection{Inversion Scheme}

[19] The nonlinear inverse problem is solved by means of a generalized least squares technique combined with a gradient method [Tarantola and Valette, 1982]. The "parameter" vector $m$ (composed of $\tau_{k}, U_{k}$, and $t_{k}$, which denote the risetime, the final slip, and the time of the rupture front arrival at subfault $k$, respectively) and the "data" vector $d$ are linked by the operator $g$ according to $d=g(m)$. The cost function minimized at each iteration $i$ is defined by

$$
\begin{aligned}
S\left(m_{i}\right)= & \frac{1}{2}\left[\left(g\left(m_{i}\right)-d_{0}\right)^{t} C_{d}^{-1}\left(g\left(m_{i}\right)-d_{0}\right)\right. \\
& \left.+\left(m_{i}-m_{0}\right)^{t} C_{m}^{-1}\left(m_{i}-m_{0}\right)\right],
\end{aligned}
$$

where $d_{0}$ is the vector of observed data, $m_{0}$ is the a priori rupture model, and $C_{m}$ and $C_{d}$ are the covariance matrix of parameter vector and data vector, respectively. We assume in the following that the covariance matrix elements are null except on the diagonals, where they equal the variance values $\sigma_{m}^{2}$ and $\sigma_{d}^{2}$, respectively.

\subsubsection{Smoothing Constraints}

[20] Equation (4) means that the solution is a trade-off between a model that fairly explains the observed data but is still close to the a priori model $m_{0}$. Such a compromise is difficult to find because it depends on the subjective level of confidence in the model $m_{0}$ and in the problem parameter- ization (fault parameters, velocity model, etc.). This trade-off can also be interpreted in terms of the degree of smoothing. Smoothing constraints are commonly used to stabilize the inversion. In the procedure adopted here, the smoothing is controlled by the parameter $\lambda$, defined as

$$
\lambda=\frac{\sigma_{m}^{2}}{\sigma_{d}^{2}} .
$$

Large values of $\lambda$ mean that the solution is allowed to strongly deviate from the initial model $m_{0}$, the main goal being to fit the data. On the contrary, small values of $\lambda$ result in smoother models. Thus, the particular choice of the $\lambda$ value significantly affects the resulting slip images. This notion is corroborated by Sekiguchi et al. [2000] and Mai and Beroza [2002], who showed that large values of $\lambda$ lead to smaller correlation lengths of the static slip. However, these authors did not quantify the potential errors in the slip roughness.

\subsection{Synthetic Tests}

[21] We generate synthetic data by a priori fixing a seismic source, a network of stations, and a propagation medium (Figure 4). The principle of the tests is then to compare the slip images inverted from the synthetic data and the input slip model. The fault plane is composed of $12 \times 7$ square subfaults with dimensions $2.5 \times 2.5 \mathrm{~km}^{2}$. This corresponds approximately to $L=2 \mathrm{~W}$, which is consistent with the database inverted source models. The static slip is defined in the wave number domain according to

$$
D_{k}\left(k_{k}, k_{y}\right)=\frac{\bar{D} L W}{\sqrt{1+\left[\left(\frac{k_{k} L}{K_{x}}\right)^{2}+\left(\frac{k_{y} W}{K_{y}}\right)^{2}\right]^{2}}} .
$$

For low wave numbers, $k \leq \sqrt{(1 / L)^{2}+(1 / W)^{2}}$, the Fourierdomain phase angles are chosen so that the slip is concentrated on the middle of the fault plane. For high wave numbers, the phase angles are random. Rupture dimensions, nucleation point, rupture velocity, and risetime are kept fixed $(v=2700 \mathrm{~km} / \mathrm{s}$ and $\tau=0.8 \mathrm{~s})$. The inversion process is then performed in the frequency band $[0.1 \mathrm{~Hz}-0.8 \mathrm{~Hz}]$, starting from an a priori model $m_{0}$ of homogeneous slip on the fault. We do not perturb the synthetic seismograms with random noise, in order to isolate the effect of the smoothing parameter on the variability of the estimated slip distributions.

[22] The roughness parameters $K_{x}$ and $K_{y}$ of the inverted slip models are next calculated for different values of the smoothing parameter $\lambda$. We first investigate an "ideal" case, in which all the model parameters are known except the static slip. Second, we test more "realistic" cases by deliberately introducing errors in model parameterization (velocity structure and fault plane geometry) and in the parameters related to the temporal rupture evolution (rupture velocity and risetime).

\subsection{Results}

\subsection{1. "Ideal" Case}

[23] The results are presented in Figure 5a. The parameters $K_{x}$ and $K_{y}$ are well retrieved for high $\lambda$ values only ( $\lambda=$ 20,000 , i.e., $\sigma_{m}^{2} \gg \sigma_{d}^{2}$ ). Small values of $\lambda$ correspond to strong smoothing and therefore lead to underestimated roughness. 

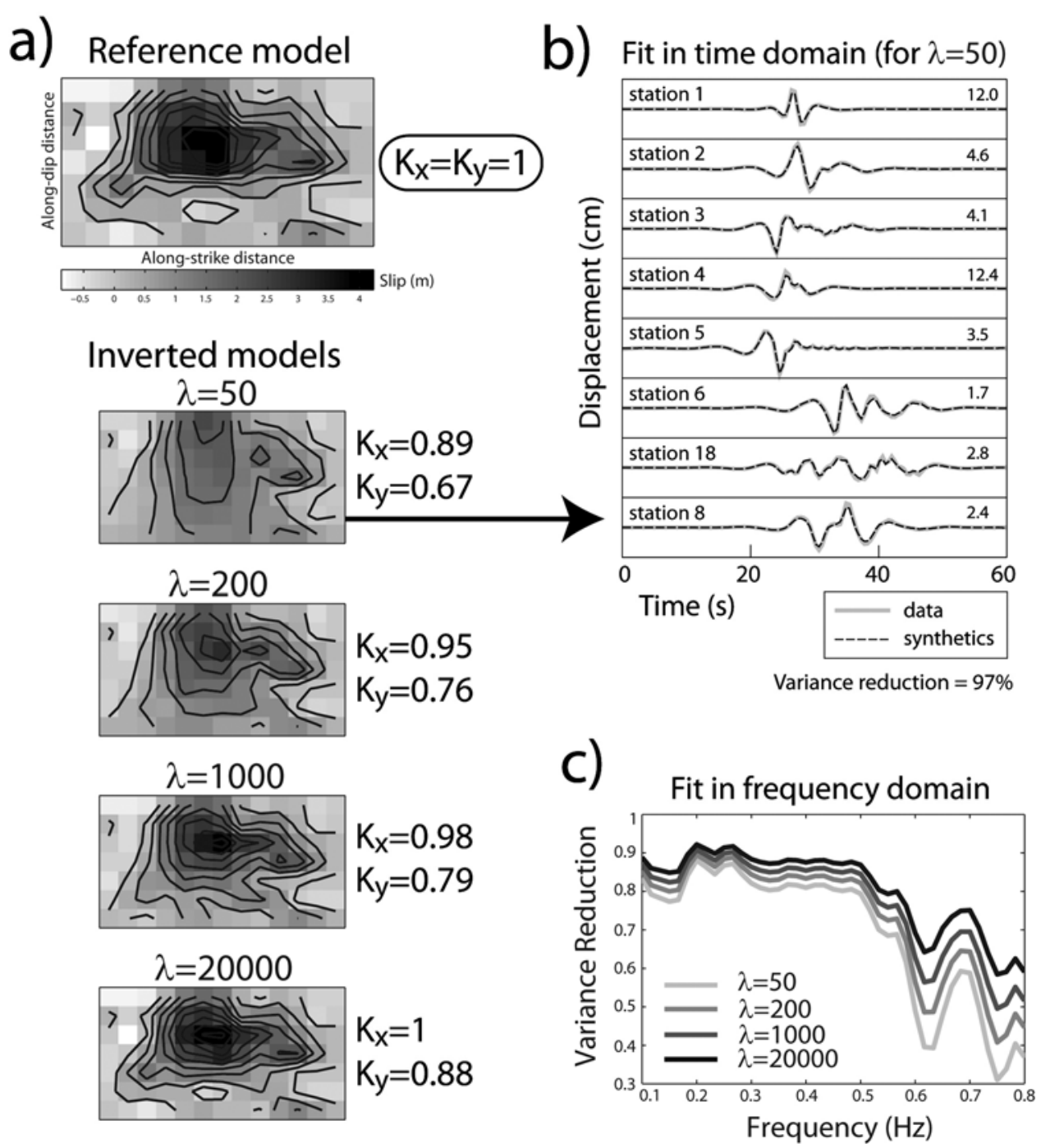

Figure 5. (a) Reference $k^{-2}$ static slip distribution and inverted models for different values of the smoothing parameter $\lambda$. The inversion process is performed by assuming that all the model and source parameters are known except the static slip. Mean slip equals $0.7 \mathrm{~m}$. The space between the contour lines is $0.5 \mathrm{~m}$. (b) Comparison between data and obtained synthetic displacement in the time domain for $\lambda=50$. The maximum displacement (in centimeters) is indicated on the right. The fit is quantified by the variance reduction [Cohee and Beroza, 1994]. (c) Variance reduction in the frequency domain for all the $\lambda$ values.

Smoothing particularly affects the along-dip slip roughness $K_{y}$, with $K_{x}$ remaining more stable. Yet, the analysis of the time domain fit between data and obtained synthetics shows a very good agreement, whatever the $\lambda$ value is (Figure $5 \mathrm{~b}$ ). Evaluating the inversion results in the time domain can thus be misleading. Figure 5c displays the fit between data and synthetics in the frequency domain, exhibiting how the fit is affected by the degree of smoothing at high frequency $(>0.5 \mathrm{~Hz})$. In other words, the slip roughness can be properly estimated only if the high-frequency components of the data are also matched (between 0.5 and $0.8 \mathrm{~Hz}$ in our particular example). Such a condition is reached by choosing sufficiently large values of $\lambda$.

\subsection{2. "Realistic" Cases}

[24] To study more realistic cases for incompletely known velocity structure and uncertain source geometry, we generate synthetic data by introducing errors $( \pm 5 \%)$ in the velocity- density structure (Figure 6) or in the fault strike and dip values (Figure 7). We consider the two following cases: $K_{x}=$ $K_{y}=1$ ("rough" slip model, Figures 6a and 7a) and $K_{x}=K_{y}=$ 0.5 ("smooth" slip model, Figures $6 \mathrm{~b}$ and $7 \mathrm{~b}$ ). For $K_{x}=K_{y}=1$, the observed tendencies are the same as in the "ideal" case. The slip roughness is reasonably well recovered for low smoothing constraints only $(\lambda>10,000)$, and if $\lambda$ is small, the roughness underestimation is still more pronounced for $K_{y}$. If the models are not sufficiently smoothed, the noise introduced in the model parameterization propagates into the slip images. This is even clearer in the case $K_{x}=K_{y}=0.5$. For $\lambda=$ 20,000 , the resulting slip distribution is distorted by artificial slip asperities and the measured $K$ value is significantly overestimated.

[25] We also characterize the errors resulting from underestimating the spatial variability of rupture velocity or risetime (Figure 8). We generate a slip distribution, setting 


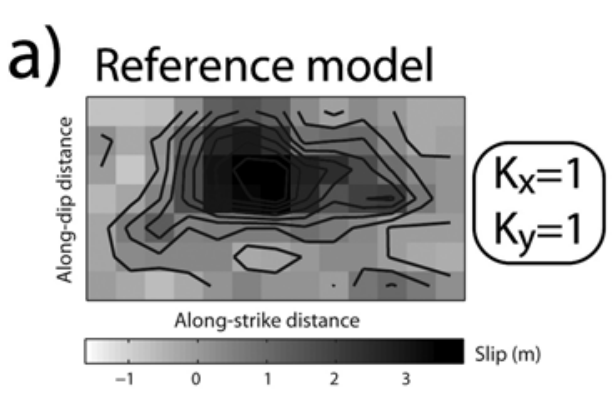

\section{Inverted models}
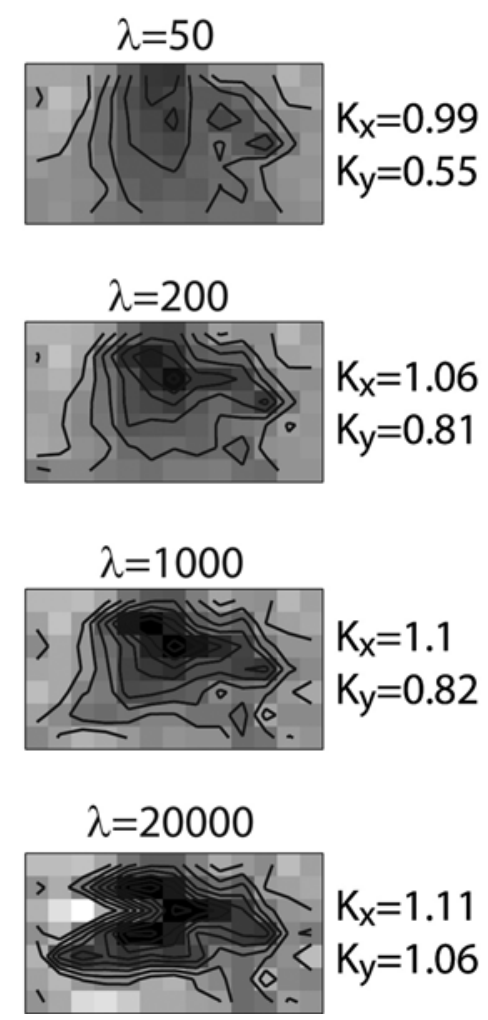

b) Reference model

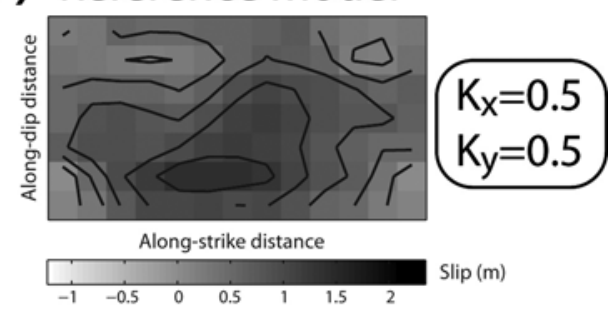

\section{Inverted models}
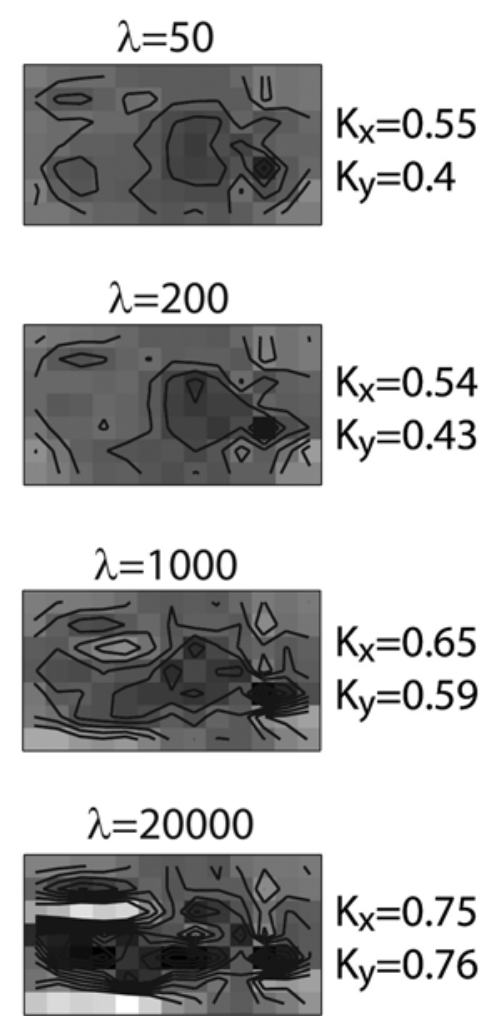

Figure 6. Results of the synthetic tests obtained by introducing errors in the velocity model $( \pm 5 \%)$ for (a) a "rough" slip distribution $\left(K_{x}=K_{y}=1\right)$ and (b) a "smooth" slip distribution $\left(K_{x}=K_{y}=0.5\right)$.

$K_{x}=K_{y}=1$, and then compute synthetic data by assigning a uniformly distributed random component to the rupture times $( \pm 10 \%)$ or to the risetimes $( \pm 20 \%)$. The inversion is then performed by assuming constant rupture velocity and risetime, fixing $\lambda=20,000$. In both cases, the resulting roughness values are larger than the one obtained in the "ideal" case, especially when considering variable rupture velocity. This overestimation is not surprising since the whole source complexity is now mapped into slip heterogeneity because the variable rupture speed and risetime are not captured in this case.

[26] The quality of the inverted slip images strongly depends on the uncertainties in the model parameterization. In the "ideal" case, the slip roughness can be accurately calculated. However, when large uncertainties exist in the model parameters, which is most probably the case for pastevent studies, the choice of the smoothing degree is fundamental. If the smoothing is too strong, the main slip characteristics (position of the main asperity) might be retrieved but the slip roughness can be biased, in particular in the along-dip direction. If no smoothing is applied, the inversion process is not stabilized and small-scale features of the static slip may only be artifacts.

\subsection{Analytical Relationship Between Ground Motion and Slip Roughness}

[27] To further constrain the potential slip roughness, we propose an approach that makes use of the growing availability of high-quality strong-motion recordings. Accelerometric databases now contain several thousands of earthquake recordings and therefore allow the development of more reliable empirical ground-motion prediction equations. These empirical equations provide an estimation of the groundmotion variability for given magnitude and distance. Thus, if a relation can be established between ground motion and slip roughness, it may be possible to indirectly assess the slip 

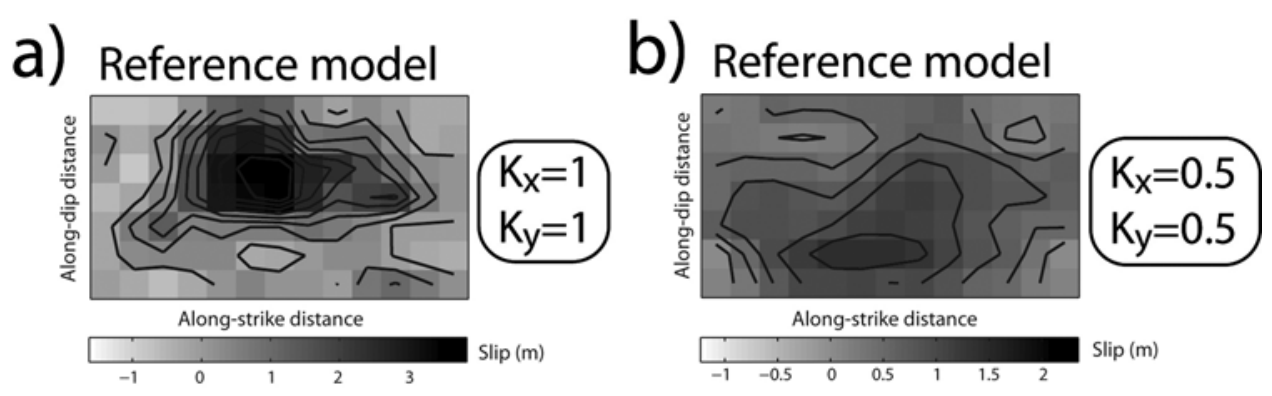

\section{Inverted models}

\section{Inverted models}
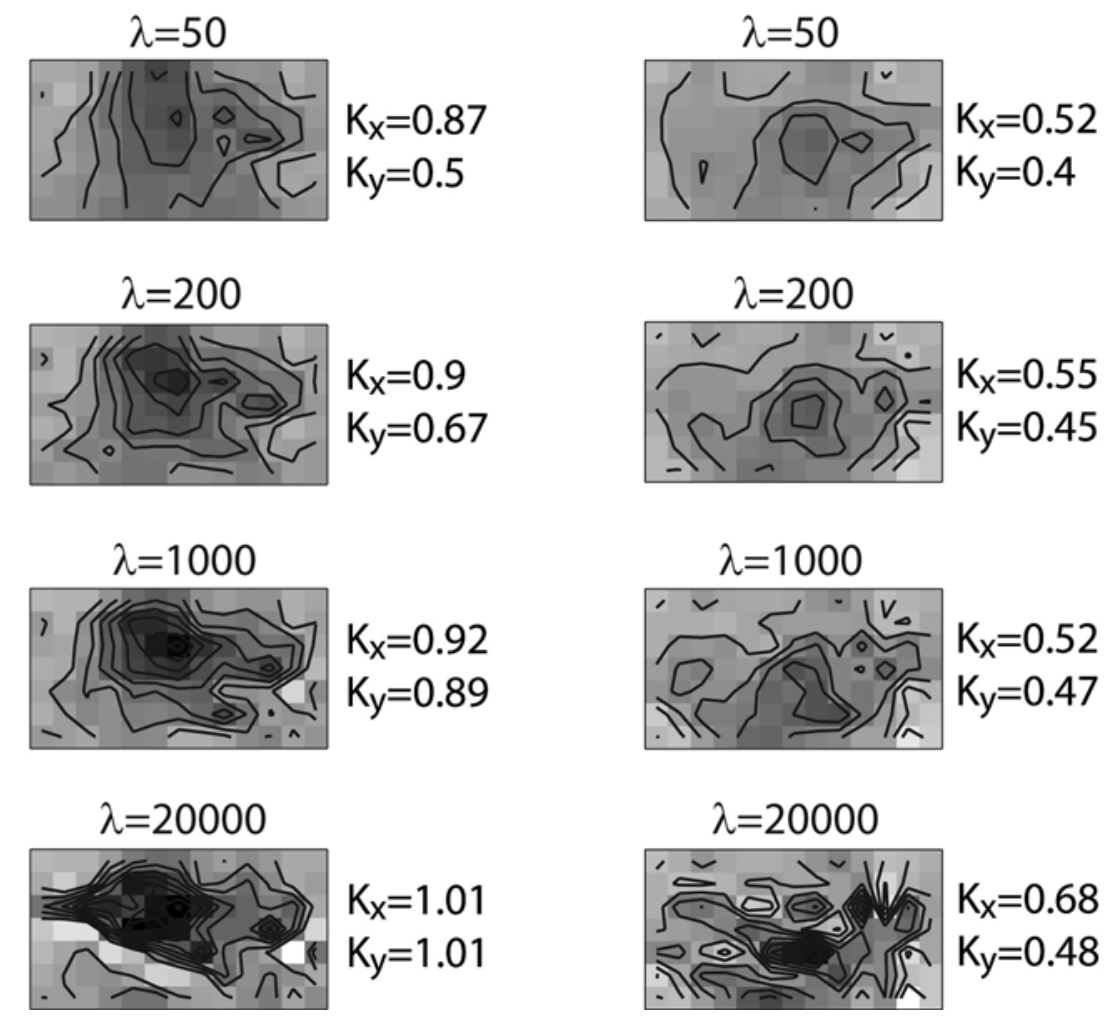

Figure 7. Results of the synthetic tests obtained by introducing errors in the fault strike and dip $\left( \pm 5^{\circ}\right)$ for (a) a "rough" slip distribution $\left(K_{x}=K_{y}=1\right)$ and (b) a "smooth" slip distribution $\left(K_{x}=K_{y}=0.5\right)$.

roughness variability under certain hypothesizes on the rupture process (Figure 9).

\subsubsection{Linking Peak Ground Acceleration (PGA)} and Corner Wave Number $\boldsymbol{k}_{c}$

[28] We consider the $k^{-2}$ kinematic model [Herrero and Bernard, 1994; Bernard et al., 1996; Gallovic and Brokesova, 2004], assuming a rectangular fault plane with dimensions $L$ and $W$ such that $L \gg W$. The rupture is supposed to propagate unilaterally only, with instantaneous slip occurring on each point on the fault. Ground motions are then computed under far-field conditions (i.e., neglecting low-frequency near-field effects). Under these hypothesizes, the analytical expression of the ground-motion acceleration amplitude spectrum is given as [Herrero and Bernard, 1994]

$$
|S(f)|=4 \pi^{2} f^{2} \cdot C_{s} \frac{M_{0}}{1+\left(f / f_{c}\right)^{2}}
$$

where $C_{s}$ contains the radiation pattern and the propagation effects. The root-mean-square acceleration is then given by

$$
a_{\mathrm{RMS}}=\sqrt{\frac{1}{T_{D}} \int_{0}^{T_{D}} S(t)^{2} d t},
$$

where $T_{D}$ denotes the rupture duration of the simulated event. Using Parseval's theorem,

$$
\int_{0}^{T_{D}} S(t)^{2} d t=\frac{1}{\pi} \int_{0}^{f_{\max }}|S(f)|^{2} d f,
$$

we combine equations (7)-(9) to obtain

$$
a_{\mathrm{RMS}}=\frac{1}{\sqrt{\pi}} 4 \pi^{2} C_{S} M_{0} \cdot \frac{1}{T_{D}} F_{c}^{2} \sqrt{\frac{f_{\max }}{F_{c}}-\frac{4}{5}} .
$$




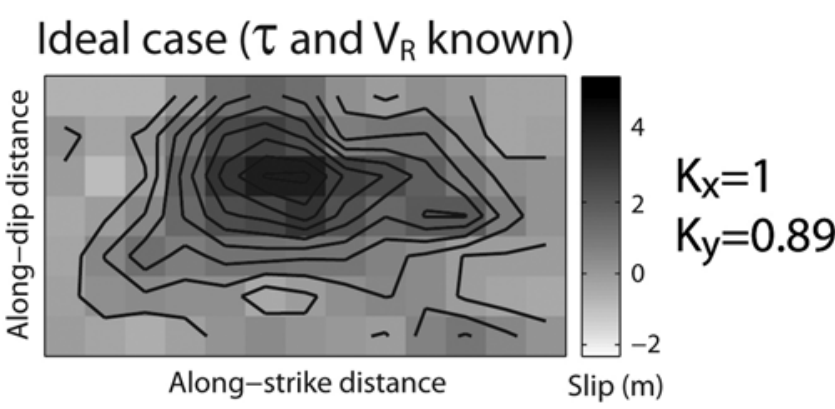

$\tau$ uncertainty effect

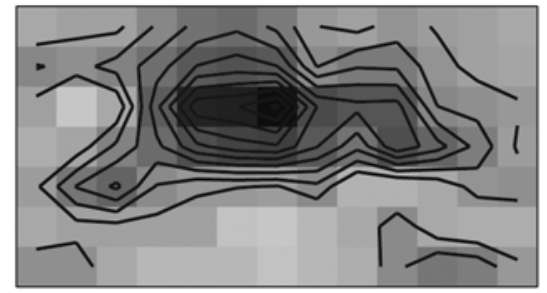

$\mathrm{K}_{\mathrm{x}}=1.06$

$\mathrm{K}_{\mathrm{y}}=0.93$

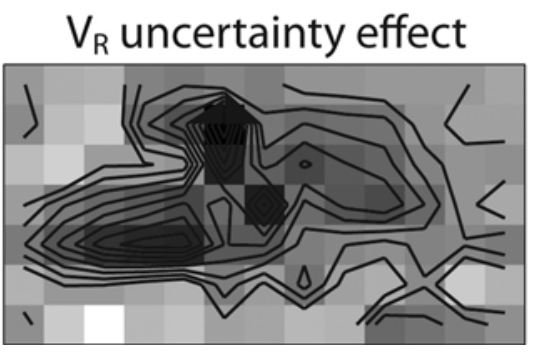

$\mathrm{K}_{\mathrm{x}}=1.23$

$K_{y}=1.37$

Figure 8. Effect on the static slip induced by underestimating the spatial variability of the risetime or the rupture velocity. Synthetic data are computed by using the $K_{x}=K_{y}=1$ reference model and by assigning a uniformly distributed random component to the risetime values $( \pm 20 \%)$ or the rupture time values $( \pm 10 \%)$. The inversion is then performed by assuming constant risetime and rupture velocity. For comparison, the ideal case is also shown (Figure 5a). In each case, $\lambda=20,000$.

For a given site and assuming constant rupture speed, the rupture duration is proportional to the fault plane length: $T_{D} \propto L$. For moderate-size and large earthquakes $\left(M_{w}>5\right)$, $f_{\max } \gg F_{c}$. Consequently, equation (9) leads to the following proportionality relation:

$$
a_{\mathrm{RMS}} \propto F_{c}^{3 / 2}
$$

The theory of stationary Gaussian random functions is then used to express PGA versus $a_{\mathrm{RMS}}$ [Vanmarcke and Lai, 1980]:

$$
\mathrm{PGA}=a_{\mathrm{RMS}} \sqrt{2 \ln \left(2 f_{\max } T_{D}\right)}
$$

Thus, by assuming that $T_{D}$ and $K$ are independent parameters, we find

$$
\mathrm{PGA} \propto F_{c}^{3 / 2}
$$

For the assumed kinematic $k^{-2}$ source model, the corner frequency is given by [Gallovic and Brokesova, 2004]

$$
F_{c}=\frac{v C_{d} K}{L}
$$

where $C_{d}=\frac{1}{1-(v / c) \cos \theta}$ is the directivity coefficient [BenMenahem, 1961]. $v$ stands for the rupture velocity, $\theta$ denotes the directivity angle, defined as the angle between the rupture propagation front and the source-receiver direction, and $c$ is the shear wave velocity. Since $C_{d}$ is constant for a given site, we obtain

$$
\mathrm{PGA} \propto\left(\frac{K}{L}\right)^{3 / 2} .
$$

We thus arrive at the desired proportionality relation between PGA and the corner wave number, valid under farfield conditions and for simple kinematic source models. Note that in this particular case, the corner wave number is defined as $k_{c}=K / L$, which means than the characteristic fault length is $L_{c}=L$. Equation (15) quantifies the expectation that slip distributions with large $k_{c}$ (i.e., very heterogeneous slip distributions) are likely to produce higher peak ground accelerations. To define the distribution of $k_{c}$ more accurately, rather than analyzing static slip images, it is hence possible to study the PGA distributions, which are usually better constrained.

\subsubsection{PGA Distribution in Empirical Ground-Motion} Equations

[29] The ground-motion variability in empirical equations is quantified by the standard deviation of the logarithm residuals, commonly referred to as "sigma." The logarithm residuals are in general normally distributed; that is, the ground-motion parameter follows a lognormal distribution [Bommer et al., 2005].

3.4.2.1. Sigma: Upper Estimation of the Variability due to Source Effects

[30] The variability sigma has multiple origins and can be split into aleatory and epistemic uncertainty. Aleatory uncertainty in this context is defined as the natural dispersion of the ground motion around the empirical model due to the inherent randomness in the physical processes governing seismic radiation and wave propagation [Mai, 2009]. It thus describes "changes in the source when there are repeated realizations of the same event on the same fault" [Anderson and Brune, 1999]. On the other hand, epistemic uncertainty comes not only from potential erroneous estimations of the model parameters (magnitude, hypocenter location, source parameters), but also from the simplicity of the functional form used to derive the empirical model. Indeed, source effects are in general accounted for only by magnitude and a term characterizing the fault mechanism in a simplified form, while path effects are modeled only by distance. Finally, site effects are often represented by standard soil classifications. Modeling earthquake complexity by such simple models leads to confusion in both epistemic and aleatory uncertainty. Consequently, sigma can be used to define the upper bound of the ground-motion variability for a single fault at a single site.

\subsubsection{Single Source and Station Ground-Motion Variability}

[31] Many classical relations result in sigma values around $0.3 \log 10$ units [e.g., Ambraseys et al., 1996; Abrahamson 


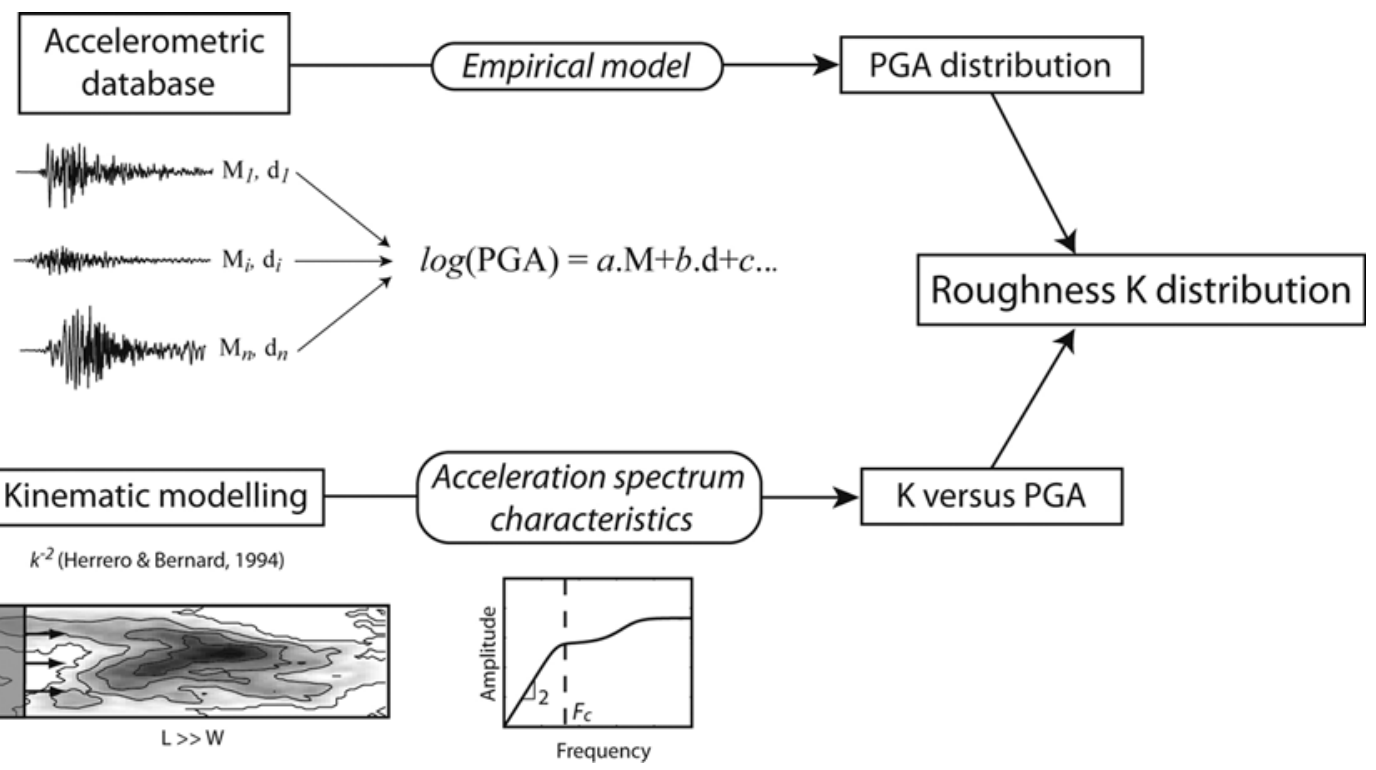

Figure 9. Principle of the "indirect" approach to assessing the variability of the slip roughness in future earthquakes, assuming a $k^{-2}$ kinematic model. A simple proportionality relationship can be established between slip roughness and peak ground acceleration (PGA). Since empirical ground-motion prediction equations provide an estimate of the PGA distribution, properties of the slip roughness distribution can be derived.

and Silva, 1997]. Douglas [2003] analyzed the groundmotion uncertainty in empirical ground-motion equations published between 1970 and 2002, reporting that the sigma value is relatively stable. However, several recent papers suggest that the ground-motion variability for a fixed site and fault is significantly less than sigma values provided by classical empirical equations. Chen and Tsai [2002] developed an algorithm to partition variability among the three components of ground motion and concluded that site conditions could contribute to almost one third of the overall variability. This finding is consistent with the study by Bragato [2008], who showed that the use of six soil categories reduced sigma by $27 \%$. Atkinson [2006] analyzed PGA residuals for earthquakes located along the Landers fault only and that had been recorded by at least 10 sites. The PGA variability obtained at a given station thus represented the variability due to source effects only. Atkinson [2006] then concluded that the PGA variability for a single fault and site might only be about $60 \%$ of the corresponding sigma value given by the regional empirical ground-motion relations.

[32] Combining these two lines of evidence, we suppose in the following that the PGA variability for a unique source and site can be approximated by

$$
\sigma\left[\log _{10}(\mathrm{PGA})\right] \approx 0.6 \cdot 0.3=0.18 .
$$

This value is consistent with the recent study of Morikawa et al. [2008], who inspected the ground-motion variability at specific stations from events selected in narrow areas by using K-NET and KiK-net records. They found sigma values ranging from 0.15 to 0.2 only. However, more detailed studies are needed, utilizing other data sets, to reach definitive conclusions about the reduction of sigma. Furthermore, although the earthquakes considered by Atkinson [2006] and
Morikawa et al. [2008] come from small regions, they have different magnitudes. The PGA variability may thus be even lower in case the idealized condition described by Anderson and Brune [1999] ("repeated realizations of the same event") does indeed hold.

\subsubsection{Slip Roughness Variability}

[33] Since PGA follows a lognormal distribution, the proportionality relation between $k_{c}$ and PGA (equation (14)) leads to a lognormal distribution for $k_{c}$. Invoking equation (15), we obtain

$$
\sigma\left[\log _{10}\left(k_{c}\right)\right] \approx 0.12
$$

Note that the distribution type and the standard deviation value are similar to those obtained from slip image analysis for $k_{c x}$, although both methods are based on different concepts (Table 2).

\section{Discussion and Conclusion}

[34] Characterizing static slip complexity of future earthquakes through the analysis of inverted slip images databases is attractive. Since it is based on "real" data, it allows for studying the natural variability of the target slip features. This "direct" approach is first used in this paper to analyze the static slip roughness. The slip roughness strongly affects the high-frequency ground motion and is thus of major interest for earthquake engineering. Nevertheless, the number of available slip models is still rather small. It is thus imperative to further enhance slip distribution databases. Note that the derived empirical model is based on very simple assumptions on the rupture physics (self-similarity) and expresses the slip roughness as a function of moment magnitude only. The use of additional parameters could probably reduce the roughness variability for a single source. For instance, 
subduction events may follow different physical processes and hence obey different scaling laws than crustal events [Scholz, 1990]. Nevertheless, performing the analysis of the database without the subduction events (Tokachi-oki in 2003, Colima in 1995, Zihuatanejo in 1985, and Michoacan in $1985)$ would not significantly change our slip roughness estimates $(\sim 3.5 \%$ reduction, see Figure $3 b)$. Furthermore, a recent study by Manighetti et al. [2007] suggests that the slip roughness depends on the structural maturity of the fault system. These authors distinguish categories of maturity (mature, intermediate, and immature), which could provide a further criterion to classify rupture types on faults.

[35] In addition, the reliability of the proposed empirical model still rests on the ability of inversion methods to accurately determine the static slip roughness. This issue has never been clearly addressed, although many studies show evidence of large uncertainties in inverted slip distributions. We therefore performed synthetics tests deploying a frequency domain inversion method. First, these tests reveal that smoothing constraints used to stabilize the inversion procedure lead to underestimated slip roughness. Consequently, the empirical model derived in this study may underestimate the slip roughness. Note that this mainly concerns the along-dip corner wave number $K_{c y}$, with $K_{c x}$ being much less sensitive to smoothing variations. Second, the limited data frequency band used to compute some slip images $(\sim<0.5 \mathrm{~Hz})$ also favor lower slip roughness. However, these models remain a minority in our database. In addition, including GPS or teleseismic data in the inversion process might tend to reduce the slip roughness as well [e.g., Wald et al., 1996; Hartzell and Heaton, 1983]. Eventually, although rupture velocity is often considered to be constant or slowly variable in inversion procedures, our tests point out that ground motion is highly sensitive to rupture time variations. Consequently, simulating ground motion by means of $k^{-2}$ models and our corner wave number estimations, assuming constant rupture velocity, may result in underestimated highfrequency energy.

[36] Note that our synthetic tests are based on a particular example for slip heterogeneity and fault plane dimensions, as well as variations in risetime and rupture speed, and need to be expanded in a future work. Moreover, as mentioned by Beresnev [2003], synthetic data do not include the whole complexity of the source process. The use of the discretized representation theorem and the assumption of $k^{-2}$ slip distributions are already strong hypothesizes on the rupture. In addition, we suppose that the rupture velocity, the source time function, and the risetime are a priori known. Hence, particular attention should be paid when interpreting the roughness characteristics obtained from kinematic inversion. Independently, the physical parameters of the propagation medium and the fault plane have to be reasonably well known, and care has to be taken when choosing smoothing constraints. A possible solution might then be to perform frequency domain inversions with a frequency-dependent smoothing degree.

[37] To further analyze slip roughness and to quantify its variability, we have developed an alternative, "indirect" method. Rather than directly analyzing inverted slip features of past events, we establish a proportionality relation between slip roughness and ground motion (PGA). The problem is then equivalent to estimating the PGA variability for given magnitude and site. Given the large amount of accelerometric data, the PGA variability is thought to be better constrained than the roughness variability resulting from slip image studies. We note, however, that the proportionality relation linking $k_{c}$ and PGA is only valid under simple hypothesizes regarding the rupture kinematics (in particular, $L \gg W$ ). The distribution type and the standard deviation obtained (lognormal with $\sigma\left[\log _{10}\left(k_{c}\right)\right] \approx 0.12$ ) are similar to the ones derived for $k_{c x}$ from our slip distribution analysis. Our study is also consistent with the results of Lavallée and Archuleta [2005]. On the basis of a very different concept, they demonstrated that both the spatial distribution of slip and the PGA theoretically follow the same probability law, under the condition that the slip distribution is characterized by a Lévy law. Such slip statistical properties have been found for several earthquakes [Lavallée and Archuleta, 2003].

[38] Acknowledgments. F.C.'s work is supported by Institut Universitaire de France. The authors would also like to thank Pierre-Yves Bard, Isabelle Manighetti, and Daniel Lavallée for their helpful comments on this paper.

\section{References}

Abrahamson, N. A., and W. J. Silva (1997), Empirical response spectral attenuation relations for shallow crustal earthquakes, Seismol. Res. Lett., $68,94-127$.

Ambraseys, N., K. A. Simpson, and J. J. Bommer (1996), Prediction of horizontal response spectra in Europe, Earthquake Eng. Struct. Dyn., 25, 371-400, doi:10.1002/(SICI)1096-9845(199604)25:4<371::AIDEQE550>3.0.CO;2-A.

Anderson, J. G., and J. N. Brune (1999), Probabilistic seismic hazard analysis without the ergodic assumption, Seismol. Res. Lett., 70, 85-96.

Antolik, M., and D. S. Dreger (2003), Rupture process of the 26 January $2001 M_{w} 7.6 \mathrm{Bhuj}$, India, earthquake from teleseismic broadband data, Bull. Seismol. Soc. Am., 93, 1235-1248, doi:10.1785/0120020142.

Asano, K., T. Iwata, and K. Irikura (2005), Estimation of source rupture process and strong ground motion simulation of the 2002 Denali, Alaska, earthquake, Bull. Seismol. Soc. Am., 95, 1701-1715, doi:10.1785/ 0120040154 .

Atkinson, G. M. (2006), Attenuation of strong ground motion in Canada from random vibrations approach, Bull. Seismol. Soc. Am., 74, 26292653.

Beeler, N. M., T. F. Wong, and S. H. Hickman (2003), On the expected relationships among apparent stress, static stress drop, effective shear fracture energy, and efficiency, Bull. Seismol. Soc. Am., 93, 13811389, doi:10.1785/0120020162.

Ben-Menahem, A. (1961), Radiation of seismic surface-waves from finite moving sources, Bull. Seismol. Soc. Am., 51, 401-435.

Beresnev, I. A. (2003), Uncertainties in finite-fault slip inversions: To what extent to believe? A critical review, Bull. Seismol. Soc. Am., 93, 24452458, doi:10.1785/0120020225.

Bernard, P., A. Herrero, and C. Berge (1996), Modelling directivity of heterogeneous earthquake ruptures, Bull. Seismol. Soc. Am., 86, 1149-1160. Bommer, J. J., F. Scherbaum, H. Bungun, F. Cotton, F. Sabetta, and N. A. Abrahamson (2005), On the use of logic trees for ground-motion prediction equations in seismic-hazard analysis, Bull. Seismol. Soc. Am., 95, 377-389, doi:10.1785/0120040073.

Bragato, P. L. (2008), Limits for the improvement of ground-motion relations in Europe and the Middle East by accounting for site effects, Bull. Seismol. Soc. Am., 98, 2061-2065.

Brune, J. N. (1970), Tectonic stress and the spectra of seismic shear waves from earthquakes, J. Geophys. Res., 75, 4997-5009, doi:10.1029/ JB075i026p04997.

Causse, M., E. Chaljub, F. Cotton, C. Cornou, and P. Y. Bard (2009), New approach for coupling $k^{-2}$ and empirical Green's functions: Application to the blind prediction of broadband ground-motion in the Grenoble basin, Geophys. J. Int., 179, 1627-1644, doi:10.11Novj.1365246X.2009.04354.x.

Chen, Y. Y., and C. C. Tsai (2002), A new method for estimation of the attenuation relationship with variance components, Bull. Seismol. Soc. Am., 92, 1984-1991, doi:10.1785/0120010205. 
Cohee, B. P., and G. C. Beroza (1994), A comparison of two methods for earthquake source inversion using strong motion seismograms, Ann. Geophys., 37, 1515-1538

Cotton, F., and M. Campillo (1995), Inversion of strong ground motion in the frequency domain: Application to the 1992 Landers, California earthquake, J. Geophys. Res., 100, 3961-3975, doi:10.1029/94JB02121.

Delouis, B., D. Giardini, P. Lundgren, and J. Salichon (2002), Joint inversion of InSAR, GPS, teleseismic, and strong-motion data for the spatial and temporal distribution of earthquake slip: Application to the $1999 \mathrm{Iz}-$ mit mainshock, Bull. Seismol. Soc. Am., 92, 278-299, doi:10.1785 0120000806.

Douglas, J. (2003), Earthquake ground motion prediction using strong motion records: A review of equations for the estimation of peak ground acceleration and response spectral ordinates, Earth Sci. Rev., 61, 43-104 doi:10.1016/S0012-8252(02)00112-5.

Dreger, D. S., L. Gee, P. Lombard, M. H. Murray, and B. Romanowicz (2005), Rapid finite-source analysis and near-fault strong ground motions: Application to the $2003 M_{w} 6.5$ San Simeon and $2004 M_{w} 6.0$ Parkfield earthquakes, Seismol. Res. Lett., 75, 40-48, doi:10.1785/ gssrl.76.1.40.

Frankel, A. (1991), High-frequency spectral falloff of earthquakes, fractal dimension of complex rupture, $b$ value, and the scaling of strength on faults, J. Geophys. Res., 96, 6291-6302, doi:10.1029/91JB00237.

Gallovic, F., and J. Brokesova (2004), On strong ground motion synthesis with the $k^{-2}$ slip distribution, J. Seismol., 8, 211-224, doi:10.1023/B: JOSE.0000021438.79877.58.

Graves, R. W., and D. J. Wald (2001), Resolution analysis of finite fault source inversion using one- and three-dimensional Green's functions. 1, J. Geophys. Res., 106, 8745-8766, doi:10.1029/2000JB900436.

Hanks, T. C. (1979), $b$ Values and $\omega^{\gamma}$ seismic source models: Implications for tectonic stress variations along active crustal fault zones and the estimation of high-frequency strong ground motion, J. Geophys. Res., 84, 2235-2242, doi:10.1029/JB084iB05p02235.

Hartzell, S. H. (1989), Comparison of seismic waveform inversion results for the rupture history of a finite fault: Application to the 1986 North Palm-Springs, California, earthquake, J. Geophys. Res., 94, 75157534, doi:10.1029/JB094iB06p07515.

Hartzell, S. H., and T. Heaton (1983), Inversion of strong ground motion and teleseismic waveform data for the fault rupture history of the 1979 Imperial Valley, California, earthquake, Bull. Seismol. Soc. Am., 73, $1555-1583$

Hartzell, S. H., and T. Heaton (1986), Rupture history of the 1984 Morgan Hill, California, earthquake from the inversion of strong motion records, Bull. Seismol. Soc. Am., 76, 649-674.

Hartzell, S. H., and M. Iida (1990), Source complexity of the 1987 Whittier Narrows, California, earthquake from the inversion of strong motion records, J. Geophys. Res., 95, 12,475-12,485, doi:10.1029/ JB095iB08p 12475 .

Hartzell, S. H., and C. Mendoza (1991), Application of an iterative leastsquares wave-form inversion of strong-motion and teleseismic records to the 1978 Tabas, Iran, earthquake, Bull. Seismol. Soc. Am., 81, 305331.

Hartzell, S. H., C. Langer, and C. Mendoza (1994), Rupture histories of eastern North American earthquakes, Bull. Seismol. Soc. Am., 85, $1703-1724$

Hartzell, S. H., P. Liu, C. Mendoza, J. Chen, and K. M. Larson (2007), Stability and uncertainty of finite-fault slip inversions: Application to the 2004 Parkfield, California, earthquake, Bull. Seismol. Soc. Am., 97, 1911-1934, doi:10.1785/0120070080.

Hernandez, B., F. Cotton, and M. Campillo (1999), Contribution of radar interferometry to a two-step inversion of the kinematic process of the 1992 Landers earthquake, J. Geophys. Res., 104, 13,083-13,099, doi:10.1029/1999JB900078.

Hernandez, B., N. M. Shapiro, S. K. Singh, J. F. Pacheco, F. Cotton, M. Campillo, A. Iglesias, V. Cruz, J. M. Gomez, and L. Alcantara (2001) Rupture history of September 30, 1999 intraplate earthquake of Oaxaca, Mexico $\left(M_{w} 7.5\right)$ from inversion of strong-motion data, Geophys. Res. Lett., 28, 363-366, doi:10.1029/2000GL011975.

Hernandez, B., M. Cocco, F. Cotton, S. Stramondo, O. Scotti, F. Courboulex, and M. Campillo (2004), Rupture history of the 1997 Umbria-Marche (central Italy) main shocks from the inversion of GPS, DInSAR and near field strong motion data, Ann. Geophys., 47, 1355-1376.

Herrero, A., and P. Bernard (1994), A kinematic self-similar rupture process for earthquakes, Bull. Seismol. Soc. Am., 84, 1216-1228.

Ide, S., and G. C. Beroza (2001), Does apparent stress vary with earthquake size? Geophys. Res. Lett., 28, 3349-3352, doi:10.1029/2001GL013106.

Kanamori, H., and L. Rivera (2004), Static and dynamic scaling relations for earthquakes and their implications for rupture speed and stress drop, Bull. Seismol. Soc. Am., 94, 314-319, doi:10.1785/0120030159.
Lavallée, D., and R. Archuleta (2003), Stochastic modelling of slip spatial complexity for the 1979 Imperial Valley, California, earthquake, Geophys. Res. Lett., 30(5), 1245, doi:10.1029/2002GL015839.

Lavallée, D., and R. Archuleta (2005), Coupling of the random properties of the source and the ground motion for the 1999 Chi Chi earthquake, Geophys. Res. Lett., 32, L08311, doi:10.1029/2004GL022202.

Lavallée, D., P. Liu, and R. Archuleta (2006), Stochastic model of heterogeneity in earthquake slip spatial distributions, Geophys. J. Int., 165, 622-640, doi:10.11Novj.1365-246X.2006.02943.x.

Liu, H., and D. V. Helmberger (1983), The near-source ground motion of the 6 August 1979 Coyote Lake, California, earthquake, Bull. Seismol. Soc. Am., 73, 210-218.

Ma, K. F., T. R. A. Song, S. J. Lee, and H. I. Wu (2001), Spatial slip distribution of the September 20,1999, Chi-Chi, Taiwan, earthquake $\left(M_{w}\right.$ 7.6) inverted from teleseismic data, Geophys. Res. Lett., 27, $3417-$ 3420, doi:10.1029/2000GL011393.

Mai, P. M. (2009), Ground motion: Complexity and scaling in the near field of earthquake ruptures, in Encyclopedia of Complexity and Systems Science, W. H. K. Lee and R. Meyers, editors, pp. 4435-4474, Springer, New York.

Mai, P. M., and G. C. Beroza (2000), Source-scaling properties from finitefault rupture models, Bull. Seismol. Soc. Am., 90, 604-615, doi:10.1785/ 0119990126.

Mai, P. M., and G. C. Beroza (2002), A spatial random field model to characterize complexity in earthquake fields, J. Geophys. Res., 107(B11), 2308, doi:10.1029/2001JB000588.

Mai, P. M., P. Spudich, and J. Boatwright (2005), Hypocenter locations in finite-source rupture models, Bull. Seismol. Soc. Am., 95, 965-980, doi: $10.1785 / 0120040111$

Mai, P.M., J. Burjanek, B. Delouis, G. Festa, C. Francois-Holden D. Monelli, T. Uchide, and J. Zahradnik (2007), Source-inversion blindtest: Initial results and further developments, Eos Trans. AGU, 88(52), Fall Meet. Suppl., S53C-08.

Manighetti, I., M. Campillo, C. Sammis, P. M. Mai, and G. King (2005), Evidence for self-similar, triangular slip distributions on earthquakes: Implications for earthquake and fault mechanics, J. Geophys. Res., 110, B05302, doi:10.1029/2004JB003174.

Manighetti, I., M. Campillo, S. Bouley, and F. Cotton (2007), Earthquake scaling, fault segmentation and structural maturity, Earth Planet. Sci. Lett., 253, 429-438, doi:10.1016/j.epsl.2006.11.004.

Mendoza, C. (1993), Coseismic slip of 2 large Mexican earthquakes from teleseismic body wave-forms: Implications for asperity interaction in the Michoacan plate boundary segment, J. Geophys. Res., 98, 8197-8210, doi:10.1029/93JB00021.

Mendoza, C., and S. H. Hartzell (1988), Inversion for slip distribution using teleseismic $P$ waveforms: North Palm Springs, Borah Peak, and Michoacan earthquakes, Bull. Seismol. Soc. Am., 78, 1092-1111.

Mendoza, C., and S. H. Hartzell (1989), Slip distribution of the 19 September 1985 Michoacan, Mexico, earthquake: Near-source and teleseismic constraints, Bull. Seismol. Soc. Am., 79, 655-669.

Mendoza, C., and S. H. Hartzell (1999), Fault-slip distribution of the 1995 Colima-Jalisco, Mexico, earthquake, Bull. Seismol. Soc. Am., 89, 1338 1344

Miyakoshi, K., T. Kagawa, H. Sekiguchi, T. Iwata, and K. Irikura (2000) Source characterization of inland earthquakes in Japan using source inversion results, in 12th World Conference on Earthquake Engineering, Abstract 1850, N. Z. Soc. for Earthquake Eng., Silverstream.

Morikawa, N., T. Kanno, A. Narita, H. Fujiwara, Y. Fukushima, and A. Guerpinar (2008), Strong motion uncertainty determined from observed records by dense network in Japan, J. Seismol., 12, 529-546, doi:10.1007/ s10950-008-9106-2.

Olson, A. H., and J. G. Anderson (1988), Implications of frequencydomain inversion of earthquake ground motions for resolving the spacetime dependence of slip on an extended fault, Geophys. J. Int., 94, 443455, doi:10.11Novj.1365-246X.1988.tb02267.x.

Scholz, C. H. (1990), The Mechanics of Earthquake and Faulting, Cambridge Univ. Press, Cambridge, U. K.

Sekiguchi, H., and T. Iwata (2002), Rupture process of the 1999 Kocaeli, Turkey, earthquake estimated from strong-motion waveforms, Bull. Seismol. Soc. Am., 92, 300-311, doi:10.1785/0120000811.

Sekiguchi, H., K. Irikura, and T. Iwata (2000), Fault geometry at the rupture termination of the 1995 Hyogo-ken Nanbu earthquake, Bull. Seismol. Soc. Am., 90, 117-133, doi:10.1785/0119990027.

Semmane, F., M. Campillo, and F. Cotton (2005a), Fault location and source process of the Boumerdes, Algeria, earthquake inferred from geodetic and strong motion data, Geophys. Res. Lett., 32, L01305, doi:10.1029/2004GL021268.

Semmane, F., F. Cotton, and M. Campillo (2005b), The 2000 Tottori earthquake: A shallow earthquake with no surface rupture and slip properties 
controlled by depth, J. Geophys. Res., 100(B3), B03306, doi:10.1029/ 2004JB003194.

Somerville, P., K. Irikura, R. Graves, S. Sawada, D. Wald, D. Abrahamson, Y. Iwasaki, T. Kawaga, N. Smith, and A. Kowada (1999), Characterizing crustal earthquake slip models for the prediction of strong ground motion, Seismol. Res. Lett., 70, 59-80.

Tarantola, A., and B. Valette (1982), Generalized nonlinear inverse problem solved using the least square criterion, Rev. Geophys. Space Phys., 20, 219-232, doi:10.1029/RG020i002p00219.

Toro, G. W., N. A. Abrahamson, and J. F. Schneider (1997), Model of strong ground motions from earthquakes in central and eastern North America: Best estimates and uncertainties, Seismol. Res. Lett., 68, 41-57.

Vanmarcke, E. H., and S. P. Lai (1980), Strong-motion duration and RMS amplitude of earthquake records, Bull. Seismol. Soc. Am., 70, 1293-1307.

Wald, D. J. (1992), Strong-motion and broad-band teleseismic analysis of the 1991 Sierra-Madre, California, earthquake, J. Geophys. Res., 97, 11,033-11,046, doi:10.1029/92JB00565.

Wald, D. J., D. V. Helmberger, and T. H. Heaton (1991), Rupture model of the 1989 Loma-Prieta earthquake from the inversion of strong-motion and broad-band teleseismic data, Bull. Seismol. Soc. Am., 81, 15401572 .
Wald, D. J., T. H. Heaton, and K. W. Hudnut (1996), The slip history of the 1994 Northridge, California, earthquake determined from strong-motion, teleseismic, GPS, and leveling data, Bull. Seismol. Soc. Am., 86, S49S70

Yagi, Y. (2004), Source rupture process of the 2003 Tokachi-oki earthquake determined by joint inversion of teleseismic body wave and strong ground motion data, Earth Planets Space, 56, 311-316.

Yagi, Y., M. Kikuchi, S. Yoshida, and T. Sagiya (1999), Comparison of the coseismic rupture with the aftershock distribution in the Hyuga-nada earthquakes of 1996, Geophys. Res. Lett., 26, 3161-3164, doi:10.1029/ 1999GL005340.

M. Causse and F. Cotton, Laboratoire de Géophysique Interne et Tectonophysique, CNRS, Institut de Recherche pour le Développement, Université Joseph Fourier, 38041 Grenoble, France. (mathieu.causse@ obs.ujf-grenoble.fr)

P. M. Mai, Division of Physical Sciences and Engineering, King Abdullah University of Science and Technology, Thuwal 23955-6900, Saudi Arabia. 